\title{
COMPETÊNCIAS EMPREENDEDORAS DOS PROPRIETÁRIOS DE ESCRITÓRIOS DE ADVOCACIA
}

Suzete Antonieta Lizote ${ }^{1}$ Miguel Angel Verdinelli ${ }^{1}$ Mário Nenevê ${ }^{1}$

Ruan Carlos Dos Santos ${ }^{1}$

${ }^{1}$ Universidade do Vale do Itajaí 


\section{COMPETENCIAS EMPREENDEDORAS DOS PROPRIETÁRIOS DE ESCRITÓRIOS DE ADVOCACIA}

Resumo: Os elevados graus de competitividade e de exigências nas demandas, principalmente no que tange as leis e normas na esfera municipal, estadual ou federal, formam um cenário no qual as ações intraempreendedoras podem representar vantagens competitivas para os escritórios de advocacia. Este estudo teve como objetivo identificar quais competências empreendedoras se manifestam nos proprietários de escritórios de advocacia localizados nos municípios de Balneário Camboriú e Itajaí / SC. A pesquisa de natureza descritiva, teve abordagem quantitativa, sendo aplicado um questionário de autopreenchimento com base no modelo de Cooley $(1990,1991)$, que destaca as competências empreendedoras em 3 conjuntos (Realização, Planejamento e Poder). Para o processamento dos dados levantados se aplicaram técnicas estatísticas descritivas. Os resultados mostraram que as competências do conjunto realização são as mais desenvolvidas nos advogados estudados. Estes achados poderão contribuir para as práticas gerenciais, possibilitando aos advogados tornarem-se agentes proativos e promotores de inovações.

Palavras-chave: Competências empreendedoras. Empreendedorismo. Escritórios de Advocacia. Proprietários.

\section{INTRODUÇÃO}

A estratégia empresarial apresenta inúmeros desafios como, por exemplo, as frequentes mudanças que ocorrem no ambiente de negócio. Contudo, para enfrentá-las e ainda prosperar, torna-se necessário que os proprietários e gestores contem com atributos que os destaquem frente à concorrência.

Se o ambiente de negócios for visto desde uma perspectiva cognitiva, em oposição à visão que considera sua existência real, os proprietários, administradores e funcionários devem apresentar competências, habilidades e atitudes. Torna-se necessário saber reconhecer oportunidades, interpretar as condições ambientais e implementar as estratégias que permitam garantir a continuidade da organização e, ainda, que proporcionem vantagens competitivas. A mutabilidade do ambiente afeta a todas as empresas, mas serão aquelas que saibam alterar sua base de recursos e capacidades, no sentido de se ajustar a um novo estado, as que se terão condições de se manter e prosperar.

As firmas que tem capacidade de se adequar com rapidez as mudanças se consideram como detentoras de orientação empreendedora, a que se define pela condição organizacional de possuir proatividade, inovatividade, assunção de riscos, autonomia e agressividade competitiva (LUMPKIN; DESS, 1996). Tais características empresariais se potencializam pelas competências empreendedoras dos gestores e colaboradores.

Diante destas colocações, pode-se afirmar que um proprietário ou gestor que seja empreendedor terá condições de desenvolver uma visão apropriada sobre os negócios, bem como saber

Organizadores:
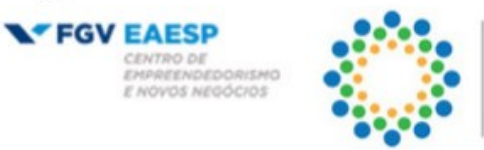

ANEGEPE
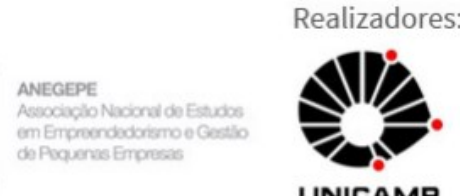
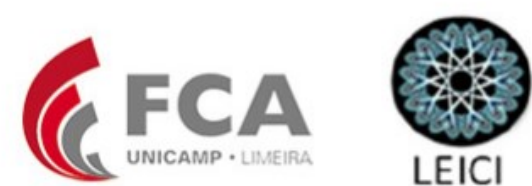
persuadir pessoas e identificar oportunidades de mercado, em particular quando os concorrentes não enxergam com clareza. Além disso, como aponta Dornelas (2003), os empreendedores têm energia, esperança e paixão pelo que fazem. Consequentemente, as pesquisas sobre a orientação empreendedora em relação ao desempenho e às características empreendedoras de proprietário e gestores têm aumentado tanto ao nível internacional como no Brasil (SILVEIRA; SILVEIRAMARTINS, 2016).

O empreendedor, conforme Filion (1999), possui alto nível de energia e alto grau de perseverança e imaginação, que combinados com a disposição para correr riscos moderados, capacita-os a transformar o que, frequentemente, começa como uma ideia ou visão simples e mal definida em algo concreto. Dornelas (2003) segue a mesma linha, observando que empreendedor é aquele que combina recursos, materiais e outros ativos para tornar seu valor maior do que antes; também é aquele que introduz mudanças, inovações e uma nova ordem.

Entende-se, desta forma, que atualmente as entidades devem adotar uma gestão empreendedora para prosperar e sobreviver no contexto de grandes mudanças. É preciso também promover a liberdade de ação em todos os níveis da empresa de modo participativo, o que deve ser a regra de conduta e orientação gerencial no processo de tomada de decisões.

Em resumo pode se dizer que os problemas complexos que surgem nos ambientes de negócios exigem que as equipes de trabalho apresentem características apropriadas para enfrenta-los e, desta forma, a ênfase direcionam-se às pessoas, seus comportamentos e modos de labor. As organizações precisam contar com trabalhadores comprometidos, capazes de perceber e perseguir oportunidades, ou seja, que tenham ou estejam dispostos a desenvolver suas competências.

Assim sendo e como uma ação de adaptação às novas realidades as empresas vêm se reestruturando e repensando seus processos de trabalho interno devido às pressões do mercado, provenientes dos consumidores, concorrentes, fornecedores, governos e, principalmente das variáveis do macro ambiente. Estas reestruturações objetivam o aumento da eficiência, com o intuito de melhor atuar nesse ambiente competitivo, garantido, desta forma a sobrevivência no mercado.

Nesta ótica, o gestor e sua equipe tem que estar preparado para enfrentar o mundo informacional e globalizado, ato este que exige tanto o saber fazer, como o saber ser. Estes imperativos são essenciais para a sobrevivência, contextualizada no aprender a aprender e podem ser traduzidos na prática de geração do crescimento organizacional através de mecanismos recursivos de formação de competências.

Ante tais realidade se focou na profissão de advogado, que é considerada como uma das principais atividades para a administração da justiça. Denota-se assim, a sua importância na sociedade, uma vez que é esse profissional quem detém a capacidade de postular os interesses das pessoas em juízo ou fora dele e também de prestar assessoria e consultoria. Sua atividade é desenvolvida de modo empresarial por meio dos escritórios de advocacia que, ao igual que outras entidades, precisam de estratégias adequadas para se manter e prosperar num mercado altamente competitivo, no qual as características empreendedoras que possuam os proprietários desempenham um papel fundamental.

Neste sentido, esta pesquisa buscará resposta ao seguinte questionamento: Quais são as competências empreendedoras que manifestam os proprietários de escritórios de advocacia que estão localizados nos Municípios de Balneário Camboriú e Itajai/SC? No intuito de dar

Organizadores:

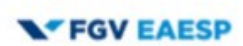

compor of

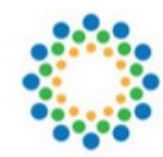

ANECEPE

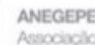

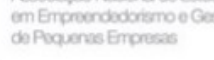

Realizadores:
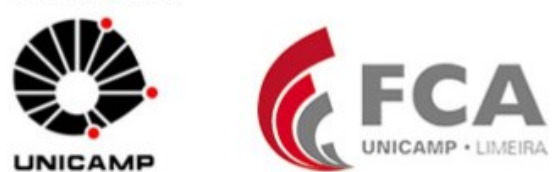

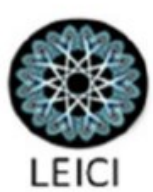


resposta a essa pergunta de pesquisa definiu-se como objetivo geral do estudo avaliar as competências empreendedoras que manifestam os proprietários escritórios de advocacia localizados Municípios de Balneário Camboriú e Itajaí/SC.

Nos últimos anos o cenário dos escritórios de advocacia tem mudado de maneira substancial, sendo que a criação e a manutenção de vantagens competitivas têm se tornado um elemento essencial para permanecer no mercado. Em decorrência disto, os proprietários ou gestores dos escritórios precisam desenvolver competências empreendedoras, a fim de saber identificar as oportunidades e gerar inovações, que irão derivar em vantagens competitivas sobre seus concorrentes.

Considerando o exposto, assinala-se a importância do estudo para os escritórios de advocacia, pois, é essencial que os advogados no ofício das suas funções desenvolvam suas competências empreendedoras, porque possuem um importante papel junto à sociedade ao prestar uma função social, cuidando dos direitos das pessoas e das empresas.

Este artigo está estruturado em cinco seções. A primeira corresponde à introdução, que apresenta a contextualização do tema, problema e o objetivo, uma breve justificativa e a estrutura do trabalho. A seção seguinte aborda a fundamentação teórica do estudo, com ênfase no construto das competências empreendedoras. Na terceira seção é apresentada a metodologia, que compreende os principais aspectos inerentes à pesquisa quantitativa e técnicas de análise. Na sequência, são apresentados e discutidos os resultados da pesquisa. Na quinta e última seção, são apresentadas as considerações finais, juntamente com as limitações e sugestões para estudos futuros.

\section{FUNDAMENTAÇÃO TEÓRICA}

Esta seção trata da fundamentação teórica que serve de suporte para este estudo. Sua organização implica no tratamento de três temas, o primeiro referido a competências de modo geral, o segundo ao empreendedorismo e o terceiro às competências empreendedoras especificamente.

\subsection{COMPETÊNCIAS}

O tema competência, como orientação para a gestão, apresenta estudos mais significativos a partir da década de 1970. Um dos precursores dessa ideia foi McClelland (1973), para quem o estoque de conhecimento, habilidades e atitudes é que define o nível de competência do indivíduo e é esse conjunto de qualificações que permite a pessoa um melhor desempenho. Autores como Boyatizis (1982), Perrenoud (1999), Zarifian (2001), Dutra (2001), Fleury e Fleury (2001, 2004), Ruas et al.(2005), dentre outros, também têm discutindo o tema.

Na visão de Fleury (2001), a competência não se limita a um estoque de conhecimentos teóricos e empíricos adquirido pelo indivíduo, nem se encontra envolvida na tarefa. Nessa linha, ressalta que a noção de competência aparece associada a verbos como: saber agir, mobilizar recursos, integrar saberes múltiplos e complexos, saber aprender, saber engajar-se, assumir responsabilidades e ter visão estratégica. Para a organização, as competências devem agregar valor econômico e social ao indivíduo, estimulando o trabalho em equipe e o autodesenvolvimento, conforme resumido na Figura 1.
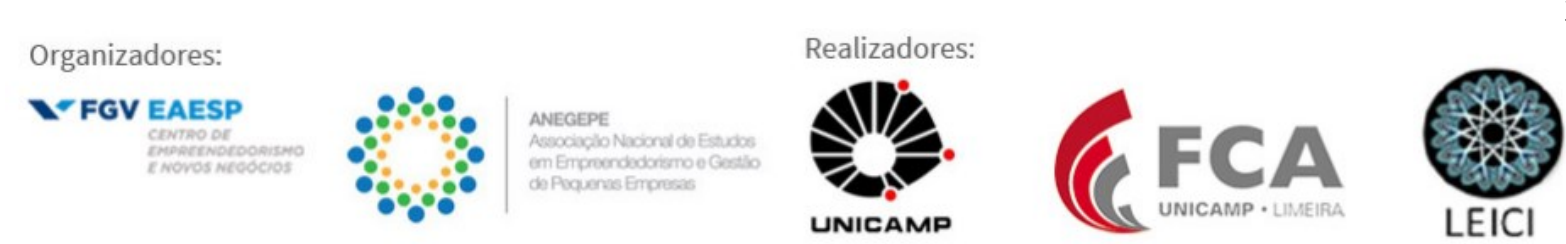
Figura 1 - Competência segundo Fleury

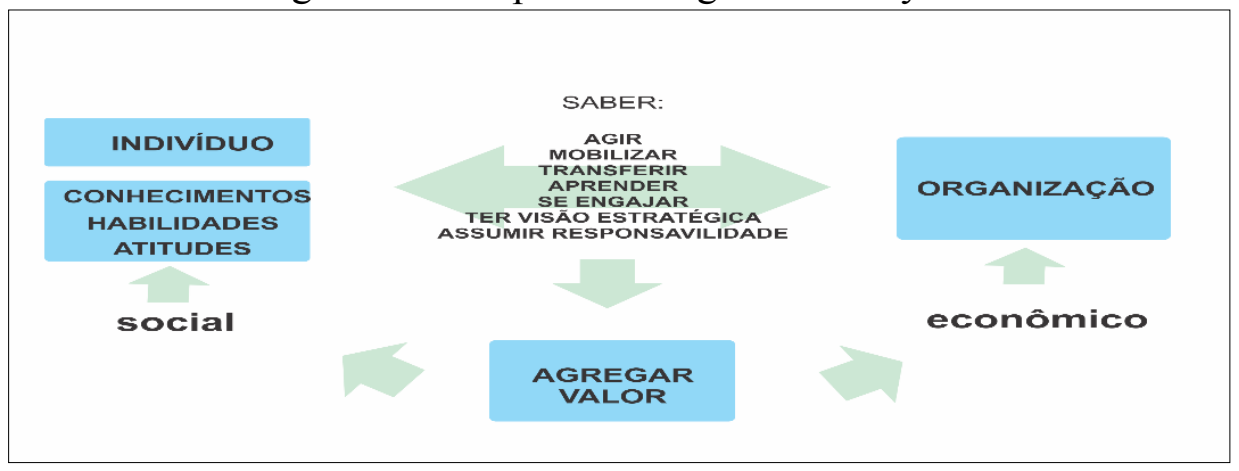

Fonte: Fleury; Fleury (2001).

Dessa forma Fleury e Fleury (2001) definem competência como um saber agir responsável e reconhecido, que implica mobilizar, integrar, transferir conhecimentos, recursos e habilidades que agregam valor econômico à organização e valor social ao indivíduo. Esse conceito é mais detalhado no Quadro 1, no qual Fleury e Fleury (2004) retomam a obra de Le Boterf (2003), quem propôs algumas definições sobre competência.

Quadro 1 - Competência segundo Le Boterf,

\begin{tabular}{|l|l|}
\hline Saber agir & Saber o que e por que faz. Saber julgar, escolher, decidir. \\
\hline Saber mobilizar recursos & Criar sinergia e mobilizar recursos e competências. \\
\hline Saber comunicar & $\begin{array}{l}\text { Compreender, trabalhar, transmitir informações, } \\
\text { conhecimentos. }\end{array}$ \\
\hline Saber aprender & $\begin{array}{l}\text { Trabalhar o conhecimento e a experiência, rever modelos } \\
\text { mentais; saber desenvolver-se. }\end{array}$ \\
\hline Saber engajar e comprometer-se & Saber empreender, assumir riscos. Comprometer-se. \\
\hline Saber assumir responsabilidades & $\begin{array}{l}\text { Ser responsável, assumindo os riscos e consequências de suas } \\
\text { ações e sendo por isso reconhecido. }\end{array}$ \\
\hline Ter visão estratégica & $\begin{array}{l}\text { Conhecer e entender o negócio da organização, o seu } \\
\text { ambiente, identificando oportunidades e alternativas. }\end{array}$ \\
\hline
\end{tabular}

Fonte: Fleury; Fleury (2004).

Competência para Nassif, Andreassi e Simões (2011, p. 38) "pode ser considerada como um último nível da característica de um indivíduo, abordando diferentes traços de personalidade, habilidades e conhecimentos, que partem das influências de experiências, treinamentos, educação, família e outras variáveis demográficas". Entanto que para Mello, Leão e Paiva Jr. (2006), a competência, consiste num corpo de conhecimento, área ou habilidade, qualidades pessoais ou características, atitudes ou visões, motivações ou direcionamentos, que podem, de diferentes formas, contribuírem para o pensamento ou ação efetiva do negócio.

Com o intuito de entender as peculiaridades do construto Competências Empreendedoras, será apresentada antes uma breve explanação sobre empreendedorismo.

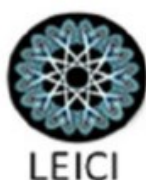




\subsection{EMPREENDEDORISMO}

Conceituar o empreendedorismo é uma tarefa complexa em função da amplitude de enfoques que dão ao tema os autores que se preocupam com seu estudo. Do ponto de vista comportamental, para Feger et al. (2008), empreendedorismo significa tomar iniciativa, organizar mecanismos sociais e econômicos para transformar recursos e situações em algo prático e aceitar o risco, bem como o fracasso. Sob um olhar psicológico, empreendedor é a pessoa impulsionada pela necessidade de obter ou conseguir algo, experimentar, realizar ou fugir da autoridade de outros (FEGER et al., 2008).

Por sua parte, para os economistas, os empreendedores são aqueles que combinam recursos, trabalho, materiais e ativos para tornar o seu valor maior que antes; é também aquele que introduz mudanças, inovações e uma nova ordem. Embora seja uma área bastante estudada permite realizar muitas pesquisas, em especial as focadas em áreas que ainda não foram abordadas, como é seu estudo no âmbito dos escritórios de advocacia.

Para ampliar o entendimento, faz-se necessário um retrospecto do processo histórico no que tange ao empreendedorismo. Segundo a relação apresentada na pesquisa de Escobar (2012), os primeiros estudos que datam do final do século XVIII e início do século XIX, com os pioneiros Richard Cantillon (1755) que introduziu o termo empreendedorismo e Jean-Baptista Say (1803), que elaborou a teoria que evidenciava as funções dos empresários, atribuindo-lhe um papel especial.

Outro pesquisador cujo trabalho é considerado seminal para esta temática foi Joseph Alois Schumpeter, para quem o empreendedor é o indivíduo capaz de aproveitar as chances das mudanças tecnológicas e introduzir processos inovadores nos mercados (SCHUMPETER, 1934). Esse autor pertenceu à escola que tem uma visão econômica do empreendedorismo.

Já o representante clássico do comportamentalismo foi Davis Clarence McClelland, que na década de 1960 desenvolveu uma teoria que busca explicar a motivação das pessoas no seu trabalho a partir da satisfação de suas necessidades. Num livro clássico aponta como um dos traços mais importantes do empreendedor a motivação para a realização ou o impulso para melhora (McCLELLAND, 1971). A partir daqueles trabalhos pioneiros o tema teve diversas vertentes de estudo sendo as principais as apresentadas no Quadro 2.

Quadro 2 - Macro abordagens do estudo do empreendedorismo.

\begin{tabular}{|c|l|l|}
\hline \multicolumn{1}{|c|}{ VERTENTES } & \multicolumn{1}{|c|}{ PERSPERCTIVAS } & \multicolumn{1}{c|}{ REFERÊNCIAS } \\
\hline \multirow{5}{*}{ Indivíduo Empreendedor } & $\begin{array}{l}\text { O empreendedor como agente } \\
\text { econômico gerador de riquezas. }\end{array}$ & $\begin{array}{l}\text { Cantillon (1931), Say (1964), } \\
\text { Smith e Miner (1985). }\end{array}$ \\
\cline { 2 - 3 } & $\begin{array}{l}\text { McClelland (1961), McClelland } \\
\text { e Burnham (1976) }\end{array}$ \\
\cline { 2 - 3 } & $\begin{array}{l}\text { Psicologia do empreendedor. } \\
\text { O empreendedor como agente de } \\
\text { inovação. }\end{array}$ & $\begin{array}{l}\text { Schumpeter (1982), Drucker } \\
\text { (1986), Baron e Shane (2007) }\end{array}$ \\
\cline { 2 - 3 } & Características do indivíduo. & $\begin{array}{l}\text { Filion (1999), Hisrich e Peters } \\
(2004)\end{array}$ \\
\cline { 2 - 3 } & O intraempreendedor. & $\begin{array}{l}\text { Kuratko e Hodgetts (1998), } \\
\text { Chisholm (1987) }\end{array}$ \\
\hline
\end{tabular}




\begin{tabular}{|c|c|c|}
\hline \multirow[b]{3}{*}{ Empreendimento } & Pequenas e médias organizações. & $\begin{array}{l}\text { Marino et al. (2002), Lechner e } \\
\text { Leyronas (2009) }\end{array}$ \\
\hline & $\begin{array}{l}\text { O empreendimento como locus de } \\
\text { inovação e desenvolvimento. }\end{array}$ & $\begin{array}{l}\text { Schumpeter (1982), Hagen } \\
(1962)\end{array}$ \\
\hline & $\begin{array}{l}\text { O empreendimento como } \\
\text { operacionalização da livre organização. }\end{array}$ & Bygrave (1997) \\
\hline \multirow{4}{*}{ Processo Empreendedor } & O processo como fenômeno complexo. & $\begin{array}{lcc}\text { Shapero } & \text { e Sokol (1982), } \\
\text { Bygrave } & (1997), \text { Aldrich e } \\
\text { Martinez } & (2001), \text { Anderson } \\
(2000) & \end{array}$ \\
\hline & Fenômeno coletivo. & $\begin{array}{l}\text { Shapero e Sokol (1982), Aldrich } \\
\text { e Martinez (2001) }\end{array}$ \\
\hline & Sobrevivência Organizacional. & $\begin{array}{l}\text { Aldrich e Martinez (2001), } \\
\text { Hannan e Freeman (2005) }\end{array}$ \\
\hline & Fases processuais. & $\begin{array}{l}\text { Baron e Shane (2007), Bygrave } \\
\text { (1997) }\end{array}$ \\
\hline
\end{tabular}

Fonte: Favoreteo et al (2012).

Como mostrado no Quadro 2, com base nas pesquisas de Favoreteo et al (2012), os estudos em empreendedorismo oscilam entre três frentes, partindo dos atributos teóricos e empírico do campo estudado. Postulam aqueles autores que ora se cuida da figura do empreendedor, considerado o protagonista do fenômeno; ora se cuida do empreendimento, resultante do esforço empreendedor; e ora se cuida do processo empreendedor, considerado a ligação por meio da qual, do primeiro, conduz-se ao segundo. No presente estudo busca-se avaliar as competências empreendedoras dos proprietários de escritórios de advocacia, portanto se trata da figura do empreendedor.

\subsection{COMPETÊNCIAS EMPREENDEDORAS}

No campo do empreendedorismo percebe-se que vários estudos vêm buscando incorporar a junção entre as características do perfil empreendedor ao contexto das competências e estas passaram, então, a assumir novas conotações. Por exemplo, Cooley (1990), a partir do modelo de competências de McClelland (1973), apresentou a divisão delas em três conjuntos.

Filion (1999) destaca que um dos primeiros autores comportamentalistas a se interessar pelos empreendedores foi Max Weber (1930). Ele identificou o sistema de valores como fundamental para explicação do comportamento empreendedor. Percebia os empreendedores como pessoas inovadoras, independentes para quem o papel de liderança nos negócios atribuía uma fonte de autoridade formal. No entanto, o pesquisador que realmente deu início à contribuição das ciências do comportamento para o empreendedorismo, foi sem dúvida, David C. McClelland (FILLION, 1999).

Foi em 1973, quando McClelland publicou o artigo "Testing for competence rather than intelligence", que se iniciou o debate entre psicólogos e administradores nos Estados Unidos. $\mathrm{O}$ autor apontou que competência é uma característica pessoal que pode estar relacionada a um desempenho superior na realização de uma tarefa. Ainda estabelece diferenças entre competência (talentos naturais de pessoas, que podem ser aprimorados), de habilidades

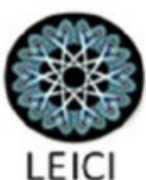


(demonstrações de talentos particulares na prática) e de conhecimento, o que a pessoa precisa saber para desempenhar uma tarefa (McCLELLAND, 1973).

Segundo sua teoria McClelland (1972) aponta que um dos traços mais importantes do empreendedor é a motivação para a realização ou o impulso para melhorar, mostrando porque algumas pessoas são mais dinâmicas que as outras, em que conclui que a necessidade de realização é importante para o seu desenvolvimento. Enfatiza que as organizações são criadas por pessoas com necessidades de pôr em prática suas ideias e, com isso, conclui que algumas características comportamentais dos líderes são bastante representativas no seu papel empresarial.

Acrescenta que a motivação humana responde, pelo menos em parte, pelo crescimento econômico de uma nação. Dessa forma, defende em sua teoria que a motivação humana compreende três necessidades dominantes: a necessidade de realização (necessidade de fazer um bom trabalho e ser reconhecido por isso), a necessidade de afiliação (é uma necessidade social) e a necessidade de poder (exprime o desejo de influenciar ou controlar). (McCLELLAND, 1972).

Embora a visão de McClelland tenha recebido diversas críticas Cooley (1991), argumenta que por mais críticas que tenha recebido, a pesquisa de McClelland continua sendo a mais ampla e mais rigorosa pesquisa empírica sobre as características associadas com empreendedores de sucesso em países em desenvolvimento.

Segundo Snell e Lau (1994), para contribuir na efetivação de um negócio, a competência empreendedora deve ser traduzida em conhecimento por área ou habilidade, em características e qualidades pessoais, objetivos, direcionamento e atitudes motivacionais.

As empresas devem estar abertas a novos projetos, de forma que os problemas não sejam considerados perdas, mas aprendizado. Isto acontece porque a inovação só advém a partir de um ambiente criativo e que atrai competências. Pinchot e Pellman (2004), já tinham afirmando que o intraempreendedorismo é o uso pela empresa do talento criativo dos líderes e colaboradores para desenvolverem produtos e serviços inovadores, o que acontece através de uma coleção de competências.

Antonello (2005) afirma que a competência empreendedora pode ser dividida em um conjunto de conhecimento, habilidades e atitudes. Entanto que Baron e Shane (2007) apresentam cinco competências sociais que podem contribuir com os empreendedores que são: a) percepção social, b) expressividade, c) administração da imagem, d) persuasão e influência e e) adaptabilidade social. Isso demonstra os vários olhares e perspectivas que podem contribuir para o conceito de competência empreendedora.

Existem competências associadas às posturas empreendedoras que auxiliam na compreensão de atributos geradores de respostas de valor na interação com grupos internos e externos da organização. Segundo Mamede e Moreira (2005), elas se vinculam ao senso de identificação de oportunidades, à capacidade de relacionamento em rede, às habilidades conceituais, à capacidade de gestão, à facilidade de leitura, ao posicionamento em cenários conjunturais e ao comprometimento com interesses individuais e da organização.

Dentre as tipologias que permitem identificação das competências empreendedoras destaca-se a utilizada por Lenzi (2008), que aborda o trabalho desenvolvido por Cooley (1990, 1991), apresentado no seminário para fundadores de empresas do Programa das Nações Unidas para o Desenvolvimento de Empreendedores (EMPRETEC). No estudo de Lenzi (2008) foram

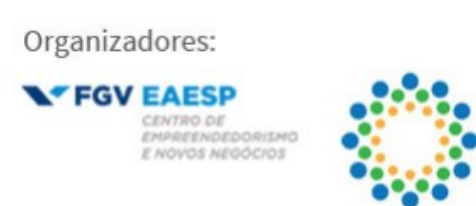

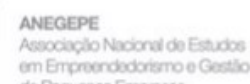

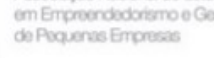


destacadas dez características de comportamento empreendedor, as chamadas competências empreendedoras. Elas são agrupadas em três conjuntos, o de realização contemplando cinco competências, o de planejamento composto por três competências e o conjunto de poder, que inclui duas competências.

Para Mello, Leão e Paiva Jr. (2006), essa junção de capacidades e conhecimentos com ações empreendedoras levaram à criação do conceito de competência, a qual consiste num corpo de conhecimento, área ou habilidade, qualidades pessoais ou características, atitudes ou visões, motivações ou direcionamentos, que podem de diferentes formas, contribuírem para o pensamento ou ação efetiva do negócio.

Antonello e Boff (2005) definiram competência empreendedora como um conjunto de conhecimentos, habilidades e atitudes que viabilizam a um indivíduo imprimir sua visão, estratégias e ações na criação de valores (intangíveis ou tangíveis) para a sociedade. Zarifian (2001) argumenta que as competências são necessárias nos diversos níveis, mas que as competências empreendedoras refletem ações eficazes do dirigente de perfil empreendedor.

Desta forma, observa-se que a gestão de competências assume papel fundamental na administração de uma organização, pois o empreendedor deve adequar-se a essa realidade considerando o perfil de seus colaboradores, assim como as suas aspirações pessoais para elevar a motivação e, consequentemente, alcançar as metas organizacionais.

\section{METODOLOGIA}

Esta pesquisa é caracterizada por sua natureza descritiva e correlacional, segundo a classificação de Hernández Sampieri et al. (2006). E pela sua abordagem deve se considerar como quantitativa. No entendimento de Hair Jr. et al. (2009), os estudos descritivos se criam e estruturam de maneira conspícua para medir as particularidades que se pretendem descrever de acordo com a pergunta de pesquisa. Nos estudos desta natureza são apresentadas as características de um fenômeno ou de uma população da qual foi extraída uma amostra, o que exige técnicas padronizadas de coleta e análise dos dados levantados (PRODANOV; FREITAS, 2013).

A abordagem quantitativa é frequentemente aplicada nos estudos descritivos, segundo aponta Richardson (1989). No entanto, esse tipo de abordagem é o meio apropriado para testar teorias objetivas e verificar a relação entre variáveis, o que constitui a natureza correlacional do estudo (HERNÁNDEZ SAMPIERI et al., 1997). Por sua vez, Malhotra (2012) salienta que com essa abordagem é possível esclarecer fenômenos, processos ou relações e, aplicando métodos estatísticos, generalizar os resultados amostrais para a população em estudo quando a amostra analisada é probabilística.

Para obtenção dos dados se optou pelo método de pesquisa survey (BABBIE, 1999), que normalmente utiliza a aplicação de questionário ou entrevista, visando à obtenção de dados, opiniões, ações ou características de determinado grupo de indivíduos representativos de uma população-alvo. Segundo Hair Jr. et al. (2009) o procedimento técnico do tipo survey tem o
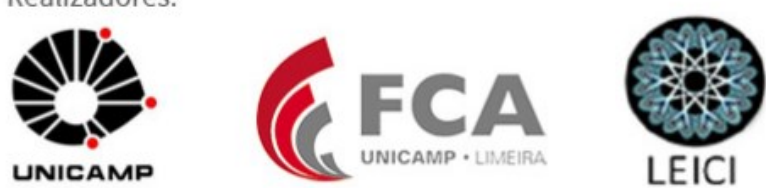
propósito de obter de modo sistemático e padronizado os dados referentes a um grupo de pessoas ou eventos que permitam identificar padrões.

O universo da pesquisa esteve composto pelos escritórios existentes nos dois municípios definidos para realizar o estudo. Entretanto, para definir a amostra a única possibilidade foi fazer um levantamento por acessibilidade. Isto é, se enviou no mês de Julho de 2017 o questionário por correio eletrônico para todos os escritórios cujos endereços constavam na lista telefônica da internet (78 em Balneário Camboriú e 95 em Itajaí) e para compor a amostra se consideram todos os instrumentos de pesquisa respondidos que chegaram no tempo definido para sua recepção. (28 e 32 em Balneário Camboriú e Itajaí respectivamente).

Embora se reconheça a importância de que a composição da amostra seja feito de modo probabilístico, teve que ser tomada por conveniência. Em geral as amostras não probabilísticas são utilizadas para pesquisas de caráter exploratório (VIRGILLITO, 2010), entretanto, é possível usá-las no sentido descritivo e relacional.

Uma vez que o construto a considerar na pesquisa foi estabelecido há que definir quais as variáveis que o refletem e, principalmente, operacionalizar sua mensuração. Segundo apontam Hair Jr. et al. (2009), para realizar isso é necessário que as variáveis sejam observáveis empiricamente e passíveis de serem medidas. Isto é, devem ser definidas como itens mensuráveis. Para tanto, se trabalhou o construto competências empreendedora a partir das dez características e cada uma delas era descrita por três afirmativas para ser respondida numa escala Likert de cinco pontos.

Nas pesquisas empíricas a coleta de dados torna-se uma das etapas mais importantes, pois a confiabilidade e a validez das informações obtidas dependem da acuracidade com que os dados foram levantados. Para este estudo os dados são de fonte primária, obtidos por meio de uma survey (BABBIE, 1999) com aplicação de um questionário junto aos proprietários de escritórios de advocacia. As pesquisas survey possibilitam a obtenção de dados ou informações sobre características, ações ou opiniões de determinado grupo de pessoas (FREITAS et al., 2000).

Para levantar os dados utilizaram-se questionários de autopreenchimento, aplicados de forma virtual e, em alguns casos de maneira presencial com os proprietários. Em função da falta de resposta foram realizados contatos telefônicos com os escritórios que não tinham respondido e aqueles que aceitaram participar da pesquisa foram visitados e solicitados a responder ao questionário.

O instrumento de coleta empregado foi elaborado conforme proposta de Cooley $(1990,1991)$, no qual as competências empreendedoras são divididas em três conjuntos. No conjunto de realização se incluíram: busca de oportunidades e iniciativas - BOI; correr riscos calculados CRC; exigência de qualidade e eficiência - EQE; persistência - PER; e, comprometimento COM. O conjunto de planejamento contemplou: busca de informação - BDI; estabelecimento de metas - EDM; e, planejamento e monitoramento sistemáticos - PMS. Por fim, no conjunto de poder as competências consideradas foram: persuasão e rede de contatos - PRC e independência e autoconfiança - IAC.

No questionário cada uma das competências é definida por meio de três afirmativas, às que o proprietário deve responder usando uma escala intervalar de cinco pontos que indicam seu grau de concordância, indo desde discordo completamente (1) até concordo totalmente (5).

Os dados coletados na survey para este estudo foram organizados numa planilha eletrônica Excel®, para realizar o pré-tratamento seguindo as recomendações em Hair Jr. et al. (2009).

\section{Organizadores:}

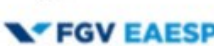

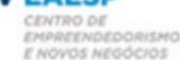

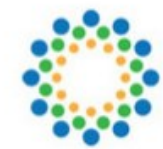

ANEGEPE

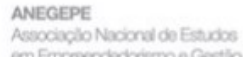

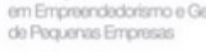

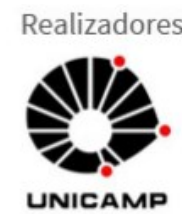


Inicialmente, foi analisado a existência de dados faltantes e erros de digitação. Caso, o número dos dados omisso não supere os $10 \%$, seja de um respondente ou de uma variável, seu valor pode ser preenchido pela média, mediana ou moda da variável em consideração. Nos dados levantados só houve dois dados faltantes e se optou por preenchê-los pela mediana.

Uma vez depurada a base de dados e realizadas os somatórios das pontuações dadas às três afirmativas que descrevem cada competência, criou-se uma nova base de dados que foi importada para o software Statistica ${ }^{\circledR}$. Com ele se calculou a média, desvio padrão, assimetria e curtose. Conforme apontam Hair Jr. et al. (2009) é através da assimetria e curtose que pode ser avaliada a normalidade dos dados e, de acordo com Finney e DiStefano (2006), valores no intervalo $[-2 ; 2]$ e $[-7 ; 7]$ respectivamente permitem considerar à distribuição como quase normal e, portanto, comparar média pelo teste t e calcular a correlação entre os municípios.

\section{RESULTADOS}

Os dados foram organizados em duas planilhas eletrônicas Excel ${ }^{\circledR}$, sendo cada uma para as respostas de cada município. Em Balneário Camboriú o número de escritórios que responderam o questionário foi de vinte e um (21) e em Itajaí trinta e dois (32). Neste segundo conjunto houve dados omissos de dois escritórios em algum item de duas competências, para persistência e para comprometimento. O procedimento adotado foi preencher o valor do somatório dos três itens com a mediana calculada para essa competência considerando os valores dos 31 outros escritórios.

Depois de realizar esses ajustes se avaliou se os somatórios das dez competências possuíam distribuição normal ou quase normal. Para tanto se calcularam as seguintes estatísticas descritivas: média, desvio padrão, assimetria e curtose. Os resultados para os dados do município de Balneário Camboriú se apresenta na Tabela 1 e os referidos a Itajaí na Tabela 2.

Tabela 1 - Estatísticas descritivas das competências medidas em Balneário Camboriú

\begin{tabular}{l|c|c|c|c}
\hline \multicolumn{1}{r|}{ Média } & Desv.Pad. & Assimetria & Curtose \\
\hline BOI & 10,905 & 2,095 & $-0,366$ & 0,234 \\
\hline CRC & 12,619 & 1,687 & $-0,503$ & $-0,683$ \\
\hline EQE & 11,238 & 2,095 & $-1,105$ & 0,886 \\
\hline PER & 12,238 & 3,390 & $-0,967$ & $-0,183$ \\
\hline COM & 12,381 & 3,294 & $-1,719$ & 2,392 \\
\hline BDI & 12,571 & 1,938 & $-1,736$ & 6,134 \\
\hline EDM & 10,762 & 1,786 & $-0,709$ & 0,855 \\
\hline PMS & 11,571 & 2,293 & $-1,642$ & 5,442 \\
\hline PRC & 12,000 & 1,924 & $-1,491$ & 4,198 \\
\hline IAC & 11,476 & 2,112 & $-0,632$ & $-0,141$ \\
\hline
\end{tabular}

Fonte: dados da pesquisa (2017).

Os valores de assimetria e de curtose demonstram que as distribuições não são normais, pois seus valores são diferentes de zero, porém encontram-se dentro dos limites sugeridos por Finney e DiStefano (2006), podendo-se considerar então como quase normais.

Tabela 2 - Estatísticas descritivas das competências medidas em Itajaí 


\begin{tabular}{l|c|c|c|c}
\hline \multicolumn{2}{r|}{ Média } & Desv.Pad. & Assimetria & Curtose \\
\hline BOI & 10,688 & 2,039 & 0,551 & 0,732 \\
\hline CRC & 12,719 & 2,331 & $-2,081$ & 5,241 \\
\hline EQE & 11,406 & 1,829 & $-0,042$ & $-0,398$ \\
\hline PER & 13,750 & 1,666 & $-1,318$ & 0,525 \\
\hline COM & 13,438 & 1,076 & $-1,320$ & 2,628 \\
\hline BDI & 12,250 & 2,095 & $-2,106$ & 6,991 \\
\hline EDM & 10,844 & 2,065 & $-2,050$ & 5,755 \\
\hline PMS & 11,875 & 2,012 & $-1,060$ & 1,447 \\
\hline PRC & 11,750 & 2,640 & $-0,867$ & 0,420 \\
\hline IAC & 11,094 & 2,911 & $-0,768$ & $-0,540$ \\
\hline
\end{tabular}

Fonte: dados da pesquisa (2017).

Da mesma forma, para os dados de Balneário Camboriú se pode constatar que as distribuições dos somatórios dos três itens de cada competência não apresentam normalidade. Ainda se constata que três competências superam ligeiramente o limite de -2 na assimetria, conforme se destaca em itálico na Tabela 2. Entretanto, optou-se por trabalhar essas competências como se fossem quase normais, isto é, sem fazer nenhuma transformação nos valores.

$\mathrm{O}$ valor do somatório de uma competência para se assumir como manifesta no caso de autoavaliação segundo Lenzi (2008) deve atingir o valor de treze (13). Isto implica que pelo menos o respondente concorde totalmente em uma das afirmativas, ou seja, pontue com cinco. Ao analisar o número de competências manifestas nos proprietários de escritórios de Balneário Camboriú se constatou que busca de oportunidades e iniciativas (BOI) esteve manifesta em 5 respondentes; correr riscos calculados (CRC) em 13; exigência de qualidade e eficiência (EQE) em 8; persistência (PER) em 13; e, comprometimento (COM) em 15. Essas cinco competências que constituem o conjunto de Realização, ao total estiveram manifestas em 54 oportunidades, representando $51,45 \%$ do total possível.

Para o conjunto Planejamento o número de vezes que se computou como manifesta a competência busca de informação (BDI) foram 10; estabelecimento de metas (EDM) apenas 4; e, planejamento e monitoramento sistemáticos (PMS) 5. Considerando que o número máximo seria 63 a porcentagem alcançada para esse conjunto foi de $30,16 \%$. Por fim, para a competência persuasão e rede de contatos (PRC) se registraram 8 competências com pontuação igual ou maior do que treze e para independência e autoconfiança (IAC) foram 6. Esses valores representam para o conjunto Poder $33,33 \%$

No caso dos proprietários de escritórios de advocacia localizados em Itajaí os números de competências manifestas do conjunto Realização foram para BOI 5, CRC 24, EQE 9, PER 26 e COM 28. Somando esses valores se chega a 92 competências manifestas de um total possível de 160 , o que representa $57,50 \%$. Para as competências do conjunto Planejamento se quantificaram os seguintes números: BDI 20, EDM 4 e PMS 14. Sua soma atinge 38 competências que tiveram pontuações de treze ou maiores, representando 39,58\% do máximo possível. No conjunto Poder a competência PRC teve 14 respondentes com pontuações iguais ou maiores do que treze e também houve 14 donos de escritórios que tiveram a competência IAC manifesta. Assim sendo, a porcentagem de competências manifestas neste conjunto chega a 43,75\%. Na Tabela 3 se exibem os números de competências manifestas.

Tabela 3 - Número de competências manifestas nos proprietários de Balneário Camboriú (BC) e de Itajaí (Itj)
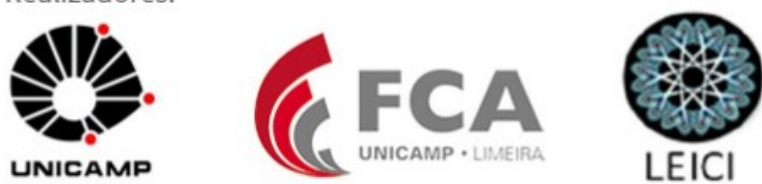


\begin{tabular}{c|c|c|c|c|c|c|c|c|c|c}
\hline & BOI & CRC & EQE & PER & COM & BDI & EDM & PMS & PRC & IAC \\
\hline BC & 5 & 13 & 8 & 13 & 15 & 10 & 4 & 5 & 8 & 6 \\
\hline Itj & 5 & 24 & 9 & 26 & 28 & 20 & 4 & 14 & 14 & 14 \\
\hline
\end{tabular}

Fonte: dados da pesquisa (2017).

A partir desses valores se fez a comparação de médias de competências manifestas para os proprietários de ambos os municípios. Na Tabela 4 se mostram as médias calculadas e o resultado do teste $t$, que permite afirmar que a média de Itajaí é estatisticamente maior que a de Balneário Camboriú com uma significância de 5\% $(\mathrm{p}<0,05)$.

Tabela 4 - Comparação do número de competências total manifestas nos proprietários de Balneário Camboriú (BC) e de Itajaí (Itj)

\begin{tabular}{c|c|c|c|c}
\hline Média BC & Média ITJ & valor $\mathbf{p}$ & g.l. & $\mathbf{p}$ \\
\hline 8,7 & 15,8 & $-2,403$ & 18 & 0,03 \\
\hline
\end{tabular}

Fonte: dados da pesquisa (2017).

Por outra parte, ao analisar as porcentagens se pode comprovar que em ambos os municípios os menores valores se têm para o conjunto Planejamento, no qual a competência que tem menor expressão foi o estabelecimento de metas. Na comparação entre os municípios se observa que para os três conjuntos de competências, o de Realização, de Planejamento e de Poder, se têm porcentagens maiores para os proprietários dos escritórios localizados em Itajaí.

Entretanto, ao verificar se as competências empreendedoras dos proprietários de ambos os municípios se associam obteve-se um coeficiente de correlação de Pearson muito significativo $(\mathrm{r}=0,923 ; \mathrm{p}<0,01)$. Dessa maneira se confirma que o comportamento dos proprietários é semelhante. As principais características mostram que as competências PER e COM são as mais representadas no conjunto Realização, no conjunto Planejamento em ambas as distribuições se tem como menos representada EDM e para o conjunto Poder os valores de competências manifestas é bastante similar para os escritórios de Balneário Camboriú e igual nos de Itajaí.

\section{CONSIDERAÇÕES FINAIS}

O estudo desenvolvido possibilitou atingir o objetivo geral proposto, que foi avaliar as competências empreendedoras que se manifestam nos proprietários de escritórios de advocacia localizados nos Municípios de Balneário Camboriú e Itajaí. Para atingir essa meta foi feito um amplo levantamento bibliográfico aos efeitos de definir o marco teórico.

Pelo uso do instrumento de pesquisa que fora utilizado por Lenzi (2008), que esteve baseado no trabalho de Cooley (1990) foi possível reunir um número de resposta adequado em ambos os municípios. Ao total se obtiveram 21 em Balneário Camboriú e 32 em Itajaí, com os quais se analisaram as competências que os proprietários manifestam.

A pesquisa mostrou que mais da metade dos proprietários tem manifestas as competências do conjunto Realização em ambos os municípios. Respeito do conjunto Planejamento comprovouse que é o menos evidenciado nos dois municípios, com destaque para a baixa realização da competência estabelecimento de metas. Por sua parte, o conjunto Poder encontra-se numa situação intermediária, com uma porcentagem de competências manifestas que é maior do que aquelas do conjunto planejamento, mas inferior às do conjunto Realização. 
Em geral, o número médio de competências manifestas difere segundo o município, sendo estatisticamente maior em Itajaí. No entanto, o comportamento das distribuições do número de competências manifestas em Balneário Camboriú tem similitude com o de Itajaí.

Uma limitação do trabalho a ser assinalada é o pequeno número de proprietários que responderam a pesquisa. Pelo que cabe sugerir repetir a pesquisa e incluir outros municípios da região.

\section{REFERÊNCIAS}

ALDRICH, H. E.; MARTINEZ, M. A. Many are called, few are chosen: an evolutionary perspective for the study of entrepreneurship. Entrepreneurship Theory and Practice, v. 25, n. 1, p. 41-56, 2001.

ANDERSSON, S. The internationalization of the firm from an entrepreneurial perspective. International Studies of Management and Organization, v. 30, n. 1, p. 65-94, 2000.

ANTONELLO, C. S. A. Metamorfose da aprendizagem organizacional: uma revisão crítica. In: RUAS, R. L.; ANTONELLO, C. S.; BOFF, L. H. e colaboradores. Os novos horizontes da gestão: aprendizagem organizacional e competências. Porto Alegre: Bookman, 2005, p. 12-33. BABBIE, Earl. Métodos de pesquisa de survey. Belo Horizonte: Ed. UFMG, 1999.

BARON, R. A.; SHANE, S. A. Empreendedorismo: uma visão do processo. São Paulo: Thomson Learning, 2007.

BOYATZIS, R. E. The competent manager: a model for effective performance. New York: John Wiley \& Sons, 1982.

BYGRAVE, W. D. The entrepreneurial process. In: BYGRAVE, William D. (Org.) The

Portable MBA in Entrepreneurship. New York: John Wiley,1997.

CANTILLON, R. Essai sur la Nature du Commerce en Général. London, UK: MacMillan, $1755 / 1931$.

CHISHOLM, T. A. Intrapreneurship and bureaucracy. S.A.M.Advanced Management Journal, v. 52, n. 3, p. 36-40, Summer 1987.

COOLEY, L. Entrepreneurship Training and the strengthening of entrepreneurial performance. Final Report. Contract. Washington: USAID, 1990.

COOLEY, L. Seminário para fundadores de empresa. Manual del Capacitador. Washington: MSI, 1991.

DORNELAS, J. C. A. Empreendedorismo corporativo: como ser empreendedor, inovar e se diferenciar em organizações estabelecidas. 2. ed. Rio de Janeiro: Elsevier, 2003.

DRUCKER, P. F. Inovação e espírito empreendedor (entrepreneurship): prática e princípios. São Paulo: Pioneira, 1986.

DUTRA, J. S. Gestão por competências: um modelo avançado para o gerenciamento de pessoas. São Paulo: Gente, 2001.

FERGER, J. E; FISCHER, A; NODARI, D. S.; ORTGARA, A. A. Empreendedores sociais privados: Reflexões sobre suas características comportamentais- RGO - Revista Gestão Organizacional. v. 1, n. 1, 2008.

FILION, L. J.. Empreendedorismo: empreendedores e proprietários-gerentes de pequenos negócios. Revista de Administração da USP, São Paulo, v. 34, n.2, p. 5-28, 1999.
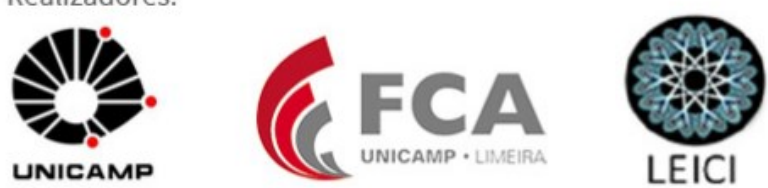
FINNEY, S. J.; DiSTEFANO, C. Non-normal and categorical data in structural equation modeling. In: G. R. HANCOK; R. O. MUELLER. Structural Equation Modeling: A Second Course. Charlotte, NC: Information Age Publishing, 2006.

FLEURY, M. T. L.; FLEURY, A. Construindo o conceito de competência. Revista de Administração Contemporânea, v. 5, n. SPE, p. 183-196, 2001.

FLEURY, A.; FLEURY, M. T. L. Estratégias empresariais e formação de competências: um quebra-cabeça caleidoscópico da indústria brasileira. 3. ed. São Paulo: Atlas, 2004.

FREITAS, H.; OLIVEIRA, M.; SACCOL, A. Z.; MOSCAROLA, J. O método da pesquisa survey. Revista de Administração, São Paulo v. 35, n.3, p. 105- 112, 2000.

GHOSHAL, S.; BARTLETT, C. A. Changing the Role of Top Management: Beyond

Structure to Process. Harvard Business Review, v. 73, n. 1, p. 86-96, 1995.

GIL, A. C. Como elaborar projetos de pesquisa. 4. ed. São Paulo: Atlas, 2002.

HAGEN, E. E. On the Theory of Social Change: How Economic Growth Begins.

Homewood: Dorsey Press, 1962.

HAIR Jr., J. F.; BLACK, W. C.; BABIN, B. J.; ANDERSON, R. E.; TATHAM R. L.; Análise multivariada de dados. 5. ed., Porto Alegre: Bookman, 2009.

HANNAN, M.; FREEMAN, J. Ecologia populacional das organizações. Revista de Administração de Empresas, v. 45, n. 3, p. 70-91, 2005.

HERNÁNDEZ SAMPIERI, R. H.; COLLADO, C. F.; LUCIO, P. B. Metodologia de pesquisa. 3. ed., São Paulo: McGraw-Hill, 2006.

HISRICH, R. D.; PETERS, M. P. Empreendedorismo. 5. ed. Porto Alegre: Bookman, 2004. KURATKO, D. F.; HODGETTS, R. M. Entrepreneurship: a contemporary approach. 4. ed, Orlando: The Dryden Press, 1998.

LE BOTERF, G. Desenvolvendo a competência dos profissionais. 3. ed. Revista e ampliada. Tradução Patrícia Chittoni Ramos Reuillard. Consultoria, supervisão e revisão técnica Claudia Bitencourt. Porto Alegre: ArtMed, 2003.

LECHNER, C.; LEYRONAS, C. Small-Business Group Formation as an Entrepreneurial Development Model. Entrepreneurship theory and practice, v. 33, n. 3, p. 645-667, 2009. LENZI, F. C. et al. Talentos inovadores na empresa. Curitiba: Ibpex, 2011.

LENZI, F. C. Os empreendedores corporativos nas empresas de grande porte: um estudo da associação entre tipos psicológicos e competências empreendedoras. 2008. Tese (Doutorado em Administração) - Faculdade de Economia, Administração e Contabilidade da Universidade de São Paulo FEA/USP. 2008.

LUMPKIN, G. T.; DESS, G. G. Clarifying the entrepreneurial orientation construct and linking it to performance. Academic of Management Review, v. 21, n. 1, p. 135-172, 1996.

MALHOTRA, N. Pesquisa de marketing: uma orientação aplicada. 6. ed. Porto Alegre: Bookman, 2012.

MAMEDE, M. I. de B.; MOREIRA, M. Z. Perfil de competências empreendedoras dos investidores Portugueses e Brasileiros: Um estudo comparativo na rede hoteleira do Ceará. In: EnANPAD: 2005. Anais... Brasília/DF.

MARINO, L.; STRANDHOLM, K.; STEENSMA, H. K.; WEAVER, K. M. The Moderating Effect of National Culture on the Relationship between Entrepreneurial Orientation and Strategic Alliance Portfolio Extensiveness. Entrepreneurial Theory \& Practice, v. 26, n. 4, p.145-160, 2002.
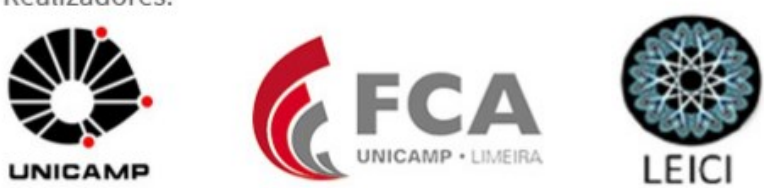
McCLELLAND, D. C. Entrepreneurship and achievement motivation: approaches to the science of socio-economic development. In: LEYGEL, P (org.). Paris: UNESCO, 1971.

McCLELLAND, D. C. The achieving society. Princeton: Van Nostrand, 1961

McCLELLAND, D. C.; BURNHAM, D. H. Power is the great motivator. Harvard Business Review, v. 54, n. 2, p. 100-110, 1976.

McCLELLAND, D. C. Entrepreneurship and achievement motivation: approaches to the science of socio-economic development. In: LEYGEL, P. (org.). Paris: UNESCO, 1971.

MELLO, S.C. B.; LEÃO, A. L. M. S.; PAIVA, F. G. Competências empreendedoras de dirigentes de empresas brasileiras de médio e grande porte que atuam em serviços da nova economia. Revista de Administração Contemporânea, Curitiba: v. 10 n. 4, 2006.

NASSIF, V. M. J.; ANDREASSI, T.; SIMÕES, F. Competências empreendedoras: há diferenças entre empreendedores e intraempreendedores? Revista de Administração e Inovação, São Paulo, v. 8, n. 3, p.33-54, 2011.

PERRENOUD, P. Construir as competências desde a escola. Porto Alegre: Artes Médicas Sul, 1999.

PINCHOT, G.; PELLMAN, R. Intraempreendedorismo na prática: um guia de inovação nos negócios. Rio de Janeiro: Elsevier, 2004.

PRODANOV, C. C.; FREITAS, E. C. Metodologia do trabalho científico: métodos e técnicas da pesquisa e do trabalho acadêmico. 2. ed. Novo Hamburgo: FEEVALE, 2013.

RICHARDSON, R. J. Pesquisa social: métodos e técnicas. São Paulo: Atlas, 1989.

ROCHA, A. C. B. Configuração de um sistema de avaliação de desempenho alicerçado no Balanced Scorecard para uma indústria de confecções de porte médio. 2002. Dissertação (Mestrado em Engenharia de Produção) - Engenharia de Produção, Universidade Federal de Santa Catarina, Florianópolis, 2002.

RUAS, R. L.; ANTONELO, C.S; BOFF, L.H. (org). Os novos horizontes da gestão: aprendizagem organizacional e competências. Porto Alegre: Bookman, 2005.

SAY, J. B. A Treatise on Political Economy, New York: Kelley, 1803/1964.

SCHMITZ, A. L. F. Competências empreendedoras: os desafios dos gestores de instituições de ensino superior como agentes de mudanças. Tese (Doutorado em Engenharia e Gestão do Conhecimento) - Centro Tecnológico, Universidade Federal de Santa Catarina, Florianópolis, 2012.

SCHUMPETER, J. A. The theory of economic development. Oxford University Press, Oxford, 1934.

SCHUMPETER, J. A. Teoria do desenvolvimento econômico. São Paulo: Abril Cultura, 1982.

SHAPERO, A.; SOKOL, L. The social dimensions of entrepreneurship. In: Encyclopedia of Entrepreneurship. Englewood Cliffs: Prentice Hall, p. 72-90, 1982.

SILVEIRA, B. R.; SILVEIRA-MARTINS, E. Orientação empreendedora: uma análise bibliométrica em periódicos nacionais e internacionais. R. Adm. FACES, v. 15 n. 4, p. 100$126,2016$.

SMITH, N. R.; MINER, J. B. Motivational considerations in the success of technologically innovative entrepreneurs: Extended sample findings. In: J. Hornaday; E. B. Shils; J. A. Timmons; K. H. Vesper (Eds.) Frontiers of entrepreneurship research. Wellesley: Babson College, p. 482-488, 1985.
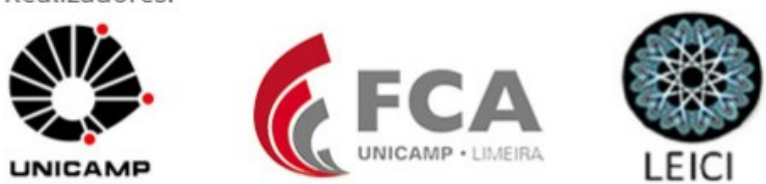
VERGARA, S. C. Projetos e relatórios de pesquisa em administração. 3. ed. São Paulo: Atlas, 2000.

VIRGILliTO, S. B. Pesquisa de marketing: uma abordagem quantitativa e qualitativa. São Paulo: Saraiva. 2010.

ZARIFIAN, P. Objetivo competência: por uma nova lógica. São Paulo: Atlas, 2001.

Atenção: número máximo de dezesseis páginas, incluindo textos, tabelas, figuras, quadros e referências. 